Seção Livre

\title{
Os Movimentos Sociais, a Ciência, a Medicalizaçáo e a Antropologia: Comentário Sobre o Artigo "Os Equívocos e Acertos da Campanha 'Náo à Medicalizaçáo da Vida”"
}

Rui Harayama ${ }^{\mathrm{I}}$

$\overline{\mathrm{I}}$ Universidade Federal de Minas Gerais (Belo Horizonte), Brasil

Outro ponto que merece destaque é que a Campanha chama a atenção para a necessidade de modernizar as práticas educativas no Brasil. Exigir o rigor científico, não só nas pesquisas sobre o assunto, mas na atualização da literatura e no cuidado ao repassar as informaçóes para a população leiga. (Frias \& Júlio-Costa, 2013, p. 9) [grifo nosso]

A epígrafe deste texto é o parágrafo com o qual os autores do artigo "Os equívocos e acertos da Campanha 'Não à medicalização da vida'” iniciam a conclusão de sua exposição, cujos objetivos são:

1. explicar melhor a tese da medicalizaçáo e a tese da construção social da doença, apresentadas como argumentos pela Campanha "Não à Medicalização da Vida" (todos os textos disponibilizados no site Fórum sobre Medicalização da Educação e da Sociedade seráo considerados endossados pela Campanha) e;

2. apresentar respostas a esses argumentos, especialmente por meio de evidências científicas sobre os transtornos de aprendizagem e TDAH. (Frias \& Júlio-Costa, 2013, p. 4)

Como membro do Fórum sobre Medicalização da Educação e da Sociedade e antropólogo com pesquisas no campo da ciência e da medicina, acredito ser necessário evidenciar alguns vícios de dados e metodologia apresentados nessa publicação, assim como discordar de algumas formulações do artigo, e, dessa forma, discutir o tema da medicalizaçáo da vida com um maior rigor científico.

\section{Do Fórum sobre Medicalizaçáo da Educação e da Sociedade}

O Fórum sobre Medicalização da Educação e da Sociedade (que a partir de agora cito como Fórum) foi criado em novembro de 2010, após o I Seminário Internacional "A Educação Medicalizada: Dislexia, TDAH e outros supostos transtornos", ocorrido na cidade de São Paulo.
Para explicitar a natureza desse Fórum, acho importante citar a passagem do documento "Subsídios para a Campanha 'Não à Medicalização da Vida”. Nesse documento, não analisado por Frias e Júlio-Costa (2013) e que foi lançado junto com a campanha foco do artigo, podemos compreender o processo de criação do Fórum:

Para realizar esta discussão [da medicalização] na sociedade e trazer questóes a respeito desse tema, compreender que aspectos estão subjacentes a essa crescente medicalização da vida, um grupo de pesquisadores de universidades públicas e privadas, entidades do magistério, da psicologia e do meio médico, das profissóes afins das áreas de saúde e educação, parlamentares, movimentos sociais se articularam para levar à população essa reflexão e mostrar que interesses estão encobertos pelas formas como determinadas saídas para a vida estáo sendo apresentadas a nós.

Essa organização permitiu a constituição do Fórum sobre Medicalização da Educação e da Sociedade, que tem como objetivos: articular entidades, grupos e pessoas para o enfrentamento e superação do fenômeno da medicalização, bem como mobilizar a sociedade para a crítica à medicalização da aprendizagem e do comportamento. O caráter do Fórum é político e de atuação permanente, constituindo-se a partir da qualidade da articulação de seus participantes e suas decisóes serão tomadas, preferencialmente, por consenso. É composto por entidades, movimentos e pessoas que tenham interesse no tema e afinidade com os objetivos do Fórum. (Conselho Federal de Psicologia, 2012, p. 5-6)

Ou seja, enquanto movimento político, o Fórum foi criado com o apoio de diversas entidades de naturezas distintas - faculdades, conselhos pro- 
fissionais, sindicatos, movimentos sociais - e por profissionais e intelectuais individuais que atuam nos serviços de saúde e educaçáo ou que apresentam reflexōes acadêmico-políticas nesse campo. $\mathrm{O}$ modelo de fórum, ao invés do modelo de associação ou de organização não governamental, gera uma dinâmica de atuaçáo capilarizada de todos os participantes. Prioridade em nossa atuaçáo, como atesta nosso manifesto, é o de ampliar a democratização do debate sobre o processo da medicalizaçáo. É nesse sentido que, como Fórum, evidenciamos a medicalização e as consequências do seu processo em diferentes arenas: publicações acadêmicas, seminários científicos, audiências públicas, redes sociais e campanhas para o público. É no bojo dessas açóes voltadas para o público em geral que se insere a campanha "Náo à Medicalização da Vida", do Conselho Federal de Psicologia, e é nesse ponto que o artigo inverte a lógica e a organização do Fórum.

O Fórum, ao invés de seguir "um movimento comandado pelo Conselho Federal de Psicologia (CFP) e pelo Conselho Regional de Psicologia de São Paulo (CRP/SP)" (Frias \& Júlio-Costa, 2013, p. 3), é aquele que pauta e insere a temática da medicalização nos conselhos profissionais, entidades de classe, dentro da academia e para o público em geral. $\mathrm{Ou}$ seja, ao contrário do que faz acreditar o artigo, os documentos e publicaçôes que criticam o processo da medicalizaçáo não se limitam ao Sistema de Conselhos de Psicologia e, tampouco, à atuação do Fórum; o processo de medicalização é estudado e criticado em diversos países.

\section{Os Movimentos Sociais e a Indústria Farmacêutica}

Se a literatura internacional vem denunciando os processos de medicalizaçáo e a cooptaçáo da academia e dos profissionais da saúde pela indústria farmacêutica (Abadie, 2010; Light, 2010; Shah, 2006), no Brasil, é com certeza a atuação político-acadêmica dos membros do Fórum que tem pautado outros setores e grupos nacionais que têm forte ligação com a indústria farmacêutica. E não é à toa que o artigo cita, como uma das críticas à nossa contestação da existência do Transtorno do Déficit de Atenção com Hiperatividade (TDAH), a "Carta aberta à sociedade sobre diagnóstico, tratamento e políticas públicas relativas aos transtornos de aprendizagem e ao transtorno do déficit de atenção e hiperatividade", um documento escrito pela
Associação Brasileira de Neuropsicologia e Associação Brasileira de Psiquiatria e divulgada pela Associação Brasileira de Déficit de Atenção (ABDA). A ABDA, cujo sítio é http://www.tdah.org.br/, expóe, em sua página principal, uma série de apoios, incluindo indústrias farmacêuticas como a Janssen, Novartis e Shire. Em comum, essas farmacêuticas citadas produzem medicamentos para o tratamento do TDAH, o Concerta ${ }^{\oplus}$, da Janssen, a Ritalina ${ }^{\oplus}$, da Novartis, e a Venvanse ${ }^{\oplus}$, da Shire.

A influência da indústria farmacêutica nos movimentos sociais e entre profissionais da saúde é de amplo conhecimento acadêmico. A relaçáo entre a indústria farmacêutica e a Associação Brasileira de Déficit de Atenção, assim como com as sociedades científicas de psiquiatria, não são casos isolados. Essa relação pode ser evidenciada no Prêmio Shire de Prática Clínica em TDAH promovido pela "Shire, em parceria com a ABENEPI, a SBNI, a ABDA e a Revista Brasileira de Psiquiatria Clínica" (www. http://premioshire.com.br/, acessado em 14 de outubro de 2013).

O prêmio Shire é um exemplo do que na literatura científica ficou descrito como sendo a presença da indústria farmacêutica na determinação do rumo das pesquisas científicas e no modo como se clinica e prescreve medicamentos. A literatura apresenta diversas análises: campanhas e eventos de conscientização de novas doenças e diagnósticos promovidos pela indústria farmacêutica para profissionais e leigos (Light, 2010), estandes em eventos científicos da área psiquiátrica com sorteio de viagens (Azize, 2010) e a estratégia dos "advogados do SUS" para a inserção de medicamentos mais caros para serem comprados pelo poder público (Chieffi \& Barata, 2010). O que esses artigos e pesquisadores ilustram é o quadro da moderna indústria farmacêutica e suas relações com a academia e movimentos sociais. Seria um argumento falacioso imaginar que qualquer profissional ou movimento social que se relacionasse com a indústria farmacêutica estivesse corrompido pelo poder do mercado, as táticas das indústrias farmacêuticas não são recebidas da mesma forma por todos os profissionais (Azize, 2010). Entretanto, para evidenciar o pressuposto da indústria farmacêutica nessa relação, gostaria de citar o texto "O que é ciência, afinal?", de minha autoria e criticado pelos autores:

Para explicar como essa intricada relação é tecida, gostaria de me concentrar no fim do 
séc. $\mathrm{XX}$, que marca a ascensão de um novo modo de ser e estar da indústria farmacêutica no mundo. O país gerador dessas mudanças são os Estados Unidos; o lobby da indústria farmacêutica inicia, em 1997, uma intervenção na política do FDA (Food and Drug Administration) e, em 1999, consegue derrubar a interdição dos anúncios e propagandas dos remédios. Com essas novas regras, a indústria farmacêutica dos Estados Unidos levou ao extremo a máxima que diz "a propaganda é a alma do negócio" deixando a cargo dos experts em marketing o comando dos setores de pesquisa e desenvolvimento de novos produtos. (Harayama, 2012)

Nesse ponto, é preciso discordar veementemente dos autores quando dizem que "é um equívoco supor que, porque o aumento da demanda de certo medicamento é bom para a indústria farmacêutica, então ele é: (a) causado pela indústria e (b) ruim para os usuários." (Frias \& Júlio-Costa, 2013, p. 8).

O processo da medicalização é exatamente esse, a criação de uma série de fatores e características transformados em diagnósticos e associados a um tipo de perfil ou grupo social que deve controlá -lo e combatê-lo. O TDAH e a reposição hormonal feminina são exemplos recentes desse movimento de medicalização, que inclui a produção de panfletos, grupos de apoio, pesquisas científicas, laboratórios em universidades e, por fim, a descoberta de tratamentos ideais, sejam eles medicamentosos ou não, para controlar a "condição biológica divergente" de certos grupos (Light, 2010). Em outras palavras, a medicalização é a apresentação contemporânea da gestão das diferenças, o que Foucault analisou em diversos escritos (Foucault, 1984; 2007).

\section{A Antropologia e a Ciência}

Entretanto, o ponto do meu maior questionamento cai sobre o que os autores chamam de "atitude anticientífica da Campanha”. E citam como exemplo o trecho:

Ciência é algo que surge quando queremos impor, ou sermos convencidos de, certos fatos incontestáveis que mudam nossa vida de forma retumbante, e que transformam os nossos desejos, quereres e poderes.
Explicado nesses termos o leitor já deve começar a perceber uma analogia de fundo: a ciência, no séc. XXI, é a nossa religião. (Harayama, 2012)

Esse parágrafo é o que abre o meu texto "O que é Ciência, afinal?”, publicado em agosto de 2012 no site www.medicalizacao.org. A proposta do texto-manifesto é explicitada em seu início:

[...] ser um anexo à Carta de Esclarecimento à Sociedade sobre o TDAH, seu diagnóstico e tratamento, escrita pela Associação Brasileira de Psiquiatria e pela Associação Brasileira de Déficit de Atenção. Como ocorre em muitos textos acadêmicos e científicos, o anexo explica muito do náo-dito no corpo do texto principal e desenvolve pontos que ficaram de fora por uma questão de restrição de tamanho ou por não serem devidamente tratados ou discutidos. É nesse segundo ponto que esse anexo se encaixa ao desenvolver o tópico central do argumento dos autores. (Harayama, 2012)

Não entrarei no mérito da forma como os autores selecionaram os trechos desse texto, e nem a predileçáo por textos-manifestos em detrimento da revisão bibliográfica de publicaçóes científicas minhas e de outros membros do Fórum. Como antropólogo, que dá preferência ao discurso nativo e do "outro", fico feliz por ver um texto de vulgarização de um movimento político sendo citado como produção científica que, nos termos dos autores, "compreende mal a ciência". E é no termo "ciência" que devemos nos ater no momento.

É inegável que os autores torcem a minha analogia entre ciência e religião como sendo anticientífica. Em antropologia, o pressuposto metodológico primordial é o de realizar pesquisas evitando o viés e olhar etnocêntrico, ou seja, evitar um olhar que traz consigo as categorias analíticas do seu grupo para entender as dinâmicas de outros. É por isso que damos prioridade ao trabalho que se faz em campo, coletando os discursos e experiências do outro e tornando-os em elementos da reflexão acadêmica. E é com esses pressupostos em mente que cabe aqui tecer alguns comentários sobre a analogia entre ciência e religião.

Analisando a história brasileira, o poder das instituiçôes religiosas sempre foi decisivo para o funcionamento da vida social e determinou a forma como 
significamos a humanidade, definindo a categoria ontológica de negros e índios, ou seja, dos que deveriam ser escravizados daqueles que deveriam ser catequizados (Almeida, 2010), até mesmo como se territorializa o espaço urbano brasileiro (Lima, 2010). É necessário ainda pontuar que essas decisóes eram discutidas e definidas por pares religiosos que traziam argumentos e evidências, em uma atuaçáo que se assemelha com a atual metodologia científica e borra a separação entre religião e ciência. Entretanto, assim como as bulas papais aceitas por diferentes formas de governos, hoje governos cada vez mais aceitam os "fatos científicos" no momento de decidir questóes de políticas públicas que definem e balizam a vida nacional. É nesse sentido que religião e ciência se assemelham: para o cidadão comum, nos dias de hoje, a comprovação científica tem equivalência a providência divina de outrora.

A imagem científica torna-se tão incontestável que grupos religiosos procuram na ciência argumentos para comprovar seus pressupostos religiosos. E é observando esses dados, da ciência e da religião como elas acontecem na vida real, vividas por seus executores, que a imagem de uma ciência pautada "pela racionalidade, entendida como a procura por evidências para sustentar afirmaçôes" (Frias \& Júlio-Costa, 2013, p. 5) é um princípio ideal, mas extremamente influenciado pelo tempo e espaço, variando na história e entre as diversas culturas.

Ora, esse pode não ser um argumento consensual em toda a academia, entretanto, é bem conhecido nos chamados science studies, ou estudos sociais da ciência, campo no qual a antropologia, a sociologia, a história e a filosofia da ciência compartilham discussôes e pesquisas sobre o fazer científico.

E é com base nessa compreensão de defender um ponto não consensual do que possa ser definido como "científico" que reitero o meu argumento publicado no texto e que vale para essa comunicação:

é preciso dizer que essa não é uma reedição tupiniquim da Science Wars que animou a academia norte-americana em fins da década de 1980. Nesse atual debate em que me insiro, não há uma questão epistemológica e científica de fundo, ou pelo menos adversários desse porte. (Harayama, 2012)

É necessário repensar os mecanismos e arranjos que determinam esse tipo de produção científica no mundo contemporâneo. Se nos dias atuais temos produzido estudos que comprovam a existência e eficácia do tratamento de distúrbios da aprendizagem com números e tabelas, o mesmo foi feito para "provar" a "inferioridade das mulheres", a "patologia da homossexualidade", a "inferioridade racial dos negros, amarelos e outras etnias não brancas". Comum nesses debates tâo antigos era a aplicação das mais refinadas técnicas científicas da época, somadas às evidências clínicas e publicaçôes científicas. É preciso reiterar que a ciência é um produto histórico-cultural e não está acima do tempo-espaço. Os chamado avanços científicos não os privam de serem produtos de um arranjo histórico-cultural específico.

\section{Do Neural ao Nacional}

A guisa de conclusão, gostaria de reiterar o fenômeno da medicalizaçáo como extremamente danoso à sociedade como um todo. Conforme citaçáo feita por Frias e Júlio-Costa (2013, p. 8)

Não estamos dentro de uma briga entre psiquiatras e psicólogos, mas observando esse momento onde há o sequestro do que consideramos saúde e doença pela indústria farmacêutica. Nossa fase histórica marca a passagem do fenômeno da construção social da doença para a produção industrial do doente. (Fusco, 2012) (sic)

Nesse ponto, nesse trecho, que foi escrito por mim em "O que é Ciência, afinal?" e erroneamente atribuído a um jornalista, que de fato entrevistara a professora de Medicina da Unicamp Maria Aparecida Moysés, concordo com os autores do artigo. Não conseguimos explicar o fenômeno da medicalização apenas nos atendo às teorias da construção social da doença. Essa teoria, muito utilizada e desenvolvida por antropólogos para compreender a doença e o sofrimento em outros povos e culturas, não consegue explicar a variedade dos fatores relacionados à produção industrial do doente, mas com certeza não é uma explicação determinante neurobiológica. Também não cabe na análise da medicalização argumentos superficiais sobre a política pública de saúde brasileira:

A questão dos transtornos de aprendizagem e do TDAH é um problema realmente de ordem pública, pois, no Brasil, apenas os mais ricos 
têm acesso a esses serviços. A falta de reconhecimento oficial impede a ajuda a essas crianças duplamente prejudicadas, pelo transtorno e pela falta de tratamento. É nesse ponto que a Campanha está equivocada. Ela está impedindo que um problema grave e solúvel seja resolvido. (Frias \& Júlio-Costa, 2013, p. 9)

Essa passagem, que é a conclusão do artigo, apenas demonstra o total desconhecimento dos autores no desenvolvimento acelerado das políticas públicas a favor dos portadores de distúrbios de aprendizagem, assim como a dispensação do Metilfenidato na rede de atenção básica no Brasil. Dados que motivam nossa ação política e acadêmica de enfrentamento da medicalização.

Concluindo essa comunicação, gostaria de parafrasear os autores e reiterar a minha inserção nesse debate enquanto intelectual e pesquisador e exigir o rigor científico, não só nas pesquisas sobre o assunto, mas na atualização da literatura e no cuidado ao repassar as informaçóes para a população leiga e a comunidade científica.

\section{Referências}

Abadie, R. (2010). The professional Guinea Pig. London: Duke University Press.

Almeida, R. A. (2010). O que é um humano? Anotaçôes sobre duas controvérsias. Dissertação de Mestrado. Programa de Pós-Graduação em Sociologia da Universidade Federal de Minas Gerais, Belo Horizonte.

Azize, R. (2010). Notas de um 'não-prescritor': uma etnografia entre os estandes da indústria farmacêutica no Congresso Brasileiro de Psiquiatria. In S. W. Maluf, \& C. S. Tornquist, Gênero, saúde e aflição: abordagens antropológicas (pp. 367-401). Florianópolis: Letras Contemporâneas.

Chieffi, A. L., \& Barata, R. D. (2010). Açōes judiciais: estratégia da indústria farmacêutica para introduçáo de novos medicamentos. Revista de Saúde Pública, 44(3), 421-429.

Conselho Federal de Psicologia. (2012). Subsidios para a Campanha Não à Medicalização da Vida. Brasília: CFP.

Foucault, M. (1984). História da sexualidade 2: o uso dos prazeres. São Paulo: Graal.

Foucault, M. (2007). A história da loucura na Idade Clássica. São Paulo: Perspectiva.
Frias, L., \& Júlio-Costa, A. (2013). Os Equívocos e Acertos da Campanha "Não à Medicalização da Vida". Psicologia em Pesquisa, 7(1), 3-12.

Harayama, R. M. (2012, Agosto). O que é ciência afinal?. Acesso em 15 de outubro de 2013, em: http://medicalizacao.org.br/o-que-e-ciencia-afinal/

Light, D. W. (2010). The Risks of Prescription Drugs. New York: Columbia University Press.

Lima, D. R. (2010). Entre as paredes de Deus: arqueologia da arquitetura sacra e do urbanismo do Serro Frio. Dissertação de Mestrado. Programa de Pós-Graduação em Antropologia Universidade Federal de Minas Gerais, Belo Horizonte.

Shah, S. (2006). The body hunters. New York: The New Press. 